\title{
Dermot Walls, Sinead T. Loughran (eds): Protein Chromatography: Methods and Protocols (Methods in Molecular Biology Series Vol. 681)
}

Humana Press, ISBN 978-1-60761-912-3

\author{
Antonio Inforzato
}

Published online: 22 January 2012

(C) Springer Science+Business Media, LLC 2012

This book has been written with the aim to provide an introduction to the complex field of protein chromatography for the benefit of biologists new to the subject as well as experienced biochemists wishing to fill common gaps in protein isolation and characterization. With this in mind, the scope of the book ranges from basic applications of protein biochemistry to more sophisticated biophysical methodologies.

More than one-third of the chapters concern the generation and purification of recombinant proteins (i.e., recombinant antibody production and protein tagging as a mean to enhance solubility and simplify purification), which reflects the major contribution of molecular biology to the field in the last 30 years. These are written in a "protocol-style" with clearly presented step-by-step methodologies, tips and explanatory notes, thus providing the reader with useful practical information. In addition, due to the vast number of variations and developments emerged over the years some topics (i.e., gel-filtration, ionexchange, and immunoaffinity chromatography) are treated and presented in an "overview-style" suitable for newcomers to these areas.
Those working in the field of proteomics will find of particular interest the chapters that illustrate applications of commonly used biophysical techniques, including surface plasmon resonance analysis of protein-protein interaction and mass spectrometric strategies. Also, emphasis is put on basic topics of protein biochemistry, such as protein stability and storage, avoiding proteolysis during chromatography and protein quantitation methods, as to stress fundamental issues often underestimated in the routine biochemistry laboratory.

As an insight into methods and principles of protein chromatography, this text has achieved all of its aims, although as an introductory text, the reader is referred to other books and journals for detailed discussion of particular techniques and applications.

Therefore, this book is much recommended to both students and experienced researchers and proves to be a valuable aid in establishing new analytical methods and/or troubleshooting major issues that arise in protein handling and purification.

\footnotetext{
A. Inforzato $(\square)$

Laboratory of Immunopharmacology, Istituto Clinico Humanitas

IRCCS, Via Manzoni 113, 20089 Rozzano, Italy

e-mail: antonio.inforzato@humanitasresearch.it
} 